\title{
Capital Budgeting and Compensation with Asymmetric Information and Moral Hazard*
}

\author{
Antonio E. Bernardo \\ Anderson School of Management at $\mathrm{UCLA}^{\dagger}$ \\ Hongbin Cai \\ Department of Economics, UCLA \\ Jiang Luo \\ Anderson School of Management at UCLA
}

July 17,2000

\begin{abstract}
We consider optimal capital allocation and managerial compensation mechanisms for decentralized firms when division managers have an incentive to misrepresent project quality and to minimize privately costly but value-enhancing effort. We show that in the optimal mechanism firms always underinvest in capital relative to a naive application of the net present value (NPV) rule. We make a number of novel cross-sectional predictions about the severity of the underinvestment problem and the composition of managerial compensation contracts. We also find that firms will optimally give greater performance-based pay (at the expense of fixed wages) to managers of higher quality projects to mitigate the incentive for managers to overstate project quality. Thus, managers may receive greater performancebased pay because they manage higher-quality projects, not that greater performance-based pay causes firm value to increase.
\end{abstract}

\footnotetext{
${ }^{*}$ We thank an anonymous referee, Bhagwan Chowdhry, Diego Garcia, Matthias Kahl, Eric Talley, Ivo Welch and seminar participants at UC Berkeley, Chicago, Hebrew University, Humboldt University, London Business School, Oxford, and Tel Aviv University for helpful comments. All errors are ours.

${ }^{\dagger}$ Corresponding author: 110 Westwood Plaza Box 951481, Los Angeles, CA, 90095-1481. tel: (310) 825-2198.
} fax: (310) 206-5455. e-mail: abernard@anderson.ucla.edu 


\section{Introduction}

Among the most important objectives of financial economics is advising firms on how to make investment decisions. Finance theory prescribes the net present value (NPV) rule which states that a firm should take an investment project when the present value of its expected future cash flows, discounted appropriately for the project's riskiness, exceeds the cost of investment. However, the NPV rule, naively applied, does not account for the information and incentive problems that can emerge in a decentralized firm. In particular, a firm's headquarters may have to rely on information about future cash flows provided by better-informed division managers. Moreover, a project's future cash flows may depend on unobservable managerial input (e.g. effort). If headquarters must provide incentives for the manager to report project quality truthfully and/or to give appropriate effort, the firm may find it optimal to allocate capital differently than prescribed by the NPV rule.

In this paper we consider a risk-neutral firm with access to capital and a single investment project. The optimal amount of capital to allocate to the project depends on its quality (i.e. expected future cash flows) which is unknown to the firm's headquarters. However, headquarters can hire a risk-neutral project manager who does know its quality. ${ }^{1}$ The division manager is assumed to enjoy private benefits from controlling more capital, reflecting a preference for "empire building" or greater perquisite consumption and reputation that comes from running a larger business. After joining the firm, the manager reports a (unverifiable) project quality to headquarters which then allocates capital according to the report. Once capital is allocated to the project, the manager can also provide input (e.g. effort) which enhances the project cash flows but is costly to the manager and unverifiable by headquarters.

Absent an explicit incentive scheme, the division manager will always wish to report the maximum project quality (to garner the greatest possible capital allocation) and will put forth the minimum amount of effort (to minimize private costs). Consequently, headquarters must use a 'disciplining device' to give the manager the incentive to report project quality truthfully and give appropriate effort. A key novel feature of our model is that we consider the role of managerial compensation contracts in this regard. Thus, for example, headquarters can reduce the manager's incentive to overstate project quality by allocating more capital and giving her greater incentive-based pay (at the expense of fixed wages) when she reports higher project quality. Moreover, headquarters can mitigate the moral hazard problem by increasing the incentive-based components of the contract. The goal of this paper is to determine jointly the

\footnotetext{
${ }^{1}$ Our paper does not address the issue of the boundaries of the firm. We simply assume that the firm has access to capital but the division manager does not so the firm's headquarters is indispensable to the production process. Gertner, Scharfstein, and Stein (1994) and Stein (1997) explicitly model the productive role of headquarters to help understand internal versus external capital markets.
} 
headquarters' optimal capital allocation and managerial compensation policy in the presence of both asymmetric information and moral hazard.

The optimal managerial contract does not generally have the manager receive zero performancebased pay because the manager would then have no incentive to give value-enhancing effort. Perhaps surprisingly, the optimal managerial contract also does not generally have the riskneutral headquarters sell the entire firm to the risk-neutral manager. In our model, this contract is not optimal because we assume that the manager knows the project quality prior to being offered the mechanism by the headquarters. ${ }^{2}$ This is a reasonable description of a situation in which a division manager meets with headquarters to discuss capital needs only after discovering a new and potentially valuable investment opportunity for the firm. ${ }^{3}$ Alternatively, our model is also a reasonable description of the case of a well-informed entrepreneur who approaches a (relatively) uninformed bank or venture capitalist to finance her new firm. ${ }^{4}$

We demonstrate that the optimal mechanism is implemented by a linear managerial compensation contract (fixed wage plus a share of the project cash flows) and a capital allocation schedule which depends on whether the reported (and, in equilibrium, the true) project quality is in one of three regions: low, intermediate, or high. For low-quality projects, headquarters allocates no capital to the project even though with symmetric information (first-best) it would be optimal to allocate positive amounts of capital for all project qualities in this region. The no-investment region is larger when the manager enjoys greater private benefits from controlling capital. For intermediate-quality projects, the firm allocates some capital but does not

\footnotetext{
${ }^{2}$ If the manager has better information about the project quality, there exists a 'lemons problem' if the firm offers to sell the firm to the manager because the manager will always want to understate the project quality in order to buy the firm at a lower price. Selling the firm to the risk-neutral manager would indeed be optimal if headquarters could offer a mechanism prior to the manager learning the project quality. In this case the riskneutral manager would bear all of the project quality risk and would do so just as efficiently as the risk-neutral shareholders. Upon learning the project quality, the manager would then allocate the first-best level of capital and effort and the first-best outcome would be achieved.

${ }^{3}$ Our model is best applied to situations in which the division manager will make a small number of large capital requests over the course of her relationship with the firm, e.g., financing R\&D in a drug which may take ten or twelve years to bring to market and then enjoy patent protection for a considerable period of time afterward. If the division manager had to meet with headquarters repeatedly to finance many projects, headquarters would have more flexibility in the capital budgeting process than we allow in our model; in particular, choosing capital allocations according to the performance of previously financed projects. This added flexibility will be most valuable when random factors have little effect on project cash flows thereby allowing headquarters to learn with great confidence whether the manager misrepresented project quality.

${ }^{4}$ Applying our model to venture capital financing is complicated by the fact that the venture capitalist is often better informed about some aspects of the business than the entrepreneur (e.g. market demand) and managerial compensation contracts may have large performance-based components because the startup firm has relatively little cash.
} 
offer profit-sharing to the manager who thus does not give any effort. The no-profit-sharing region is larger when the manager has greater effort-aversion and when effort has a smaller impact on firm value. For high-quality projects, headquarters allocates more capital and offers profit-sharing. While headquarters allocates more capital to higher quality projects, it always allocates less than the first-best level. The underinvestment problem is most severe for low-quality projects and vanishes as the project quality approaches its maximum value. Headquarters also offers greater performance-based incentives and a lower wage to the manager when she reports higher project quality. Thus, headquarters induces truthful reporting by forcing the manager to buy shares in the firm with cash when she reports that the project is high quality.

The basic intuition for these results is straightforward. By the Revelation Principle, the search for an optimal mechanism can, without loss of generality, be restricted to mechanisms that induce truthful reporting by the manager. To induce truthtelling, the optimal mechanism must provide greater information rents to the division manager when the project quality is higher. Consequently, increasing the capital allocation and managerial shareholdings for low project qualities increases information rents for such managers thereby increasing the cost of inducing truthtelling for higher project qualities. This makes the cost of allocating capital and profit-sharing prohibitive when the reported project quality is low. For projects of intermediate reported quality, the firm finds it profitable to allocate some capital but not enough to make it worthwhile to offer profit-sharing in order to induce complementary managerial effort. Finally, for projects of high reported quality, the cost of inducing truthtelling is small so headquarters allocates more capital and induces managerial effort by tying her pay directly to firm profits.

An important implication of our model is that firms without capital constraints will not necessarily fund all positive-NPV projects. Our model predicts that some positive-NPV projects will be completely unfunded and others will be underfunded which is consistent with empirical evidence that firms often require higher hurdle rates of return than predicted by standard finance theory (Poterba and Summers, 1992). We also show that firms with high R\&D expenditures, firms requiring highly firm-specific human capital, and firms with severe asymmetric information problems between division managers and headquarters will require abnormally high hurdle rates of return. Moreover, because our model with capital budgeting, asymmetric information, and moral hazard is much richer than the standard agency model based on managerial moral hazard alone, we can generate a number of novel cross-sectional predictions about the composition of managerial compensation contracts. In particular, we show how the optimal compensation contract depends on characteristics of the firm's investment opportunities (such as the degree of asymmetric information, generation of free cash flow, and the timing of cash flows) and determinants of managerial preference for capital (such as human capital specificity). Finally, our model also provides interesting insights into the relation between the form 
of managerial contracts and subsequent firm value. On one hand, greater performance-based pay induces greater managerial effort which enhances firm value. On the other hand, greater performance-based pay must be given to managers of higher-quality projects to induce truthful reporting. The latter effect states that managers receive greater performance-based pay because they manage higher-quality projects, not that greater performance-based pay causes firm value to increase. This suggests that empirical studies attempting to infer a causal link between performance-based pay and subsequent firm performance must account for the role that such incentives play in the internal capital allocation process.

Our paper is most closely related to the work of Harris and Raviv (1996) which examines capital budgeting processes in a single-division firm and Harris and Raviv (1998) which extends their earlier analysis to a multi-division firm. As in our model, these papers assume that all parties are risk-neutral and that division managers have private information about the production technology and preferences for capital. Unlike our model, however, they do not consider managerial moral hazard and they exogenously specify the manager's compensation contract. In their model, incentives are provided by a probabilistic auditing technology which allows headquarters to determine the true project quality at some fixed cost. The optimal mechanism trades off the distortion due to decentralized information and managerial preference for capital against the costs of (endogenously determined) probabilistic auditing. Interestingly, they find regions of under- and over-investment whereas we find only under-investment. We argue in Section 4 below, however, that these different predictions follow from their assumption of exogenous compensation contracts. Another advantage of our model is that it yields testable implications about observable managerial contracts whereas their model relies on auditing technologies for which there are less obvious empirical proxies.

Harris, Kriebel, and Raviv (1982) and Antle and Eppen (1985) also have models in which the division manager has private information about the production technology and preferences for capital. Unlike Harris and Raviv $(1996,1998)$, these models focus on the role of transfer prices in allocating capital across divisions as opposed to an auditing technology. As in Harris and Raviv's work, these papers find both under- and over-investment of capital but also do not consider the impact of compensation schemes in mitigating the divergence of preferences for capital between managers and headquarters. Holmstrom and Ricart i Costa (1986) consider a model in which the manager (and the market) learns about her ability by observing investment outcomes. A conflict of interest arises because the manager wishes to choose investments to maximize the value of her human capital while shareholders are only concerned about financial returns. While learning improves future decision making (causing overinvestment) it also imposes uninsurable risk on the manager (causing underinvestment) thus, unlike our model, both underinvestment and overinvestment is possible. Zhang (1997) considers a model of moral hazard in which managers with unlimited access to capital have an incentive to understate project 
quality to disguise shirking. By forcing managers to compete for capital, the firm can mitigate the incentive to understate in which case the benefit of capital rationing, increased managerial effort, can outweigh the costs, foregoing some projects, thereby resulting in underinvestment. Milbourn and Thakor (1996) consider a model with asymmetric information, moral hazard, and endogenous compensation schemes. Unlike our model, they do not assume managerial preference for capital and they do not solve explicitly for the optimal mechanism. Because they assume just two possible project types, their contract implements the first-best level of capital thus they do not predict underinvestment.

The remainder of the paper is organized as follows. Section 2 presents our model. Section 3 assumes symmetric information to derive the benchmark first-best capital and effort allocation. Section 4 describes the optimal mechanism with asymmetric information and moral hazard. We compare the second-best capital and effort allocations to the first-best levels and then derive comparative statics results and discuss their implications for empirical analysis. We then consider the robustness of our results to alternative assumptions. Section 5 concludes and gives direction for future research.

\section{The Model}

In this section we consider a simple model of a decentralized firm. The firm is run by a headquarters acting in the interest of the firm's risk-neutral shareholders. Headquarters has access to capital and a single investment project. The optimal amount of capital to invest in the project depends on its quality which is unknown to headquarters. However, headquarters can hire a risk-neutral manager who does know the project's quality. Once hired, the manager is asked to report the project quality to the headquarters which then chooses the capital allocation. Besides knowing the project quality, the manager can also enhance project cash flows by expending costly (to the manager) effort. In the specific model presented below, the manager has an incentive to overstate the quality of the project to the headquarters and an incentive to minimize her effort. The headquarters' problem will be to devise a capital allocation scheme and managerial compensation package to elicit truthful reporting and proper effort from the manager.

Specifically, we assume the project cash flows depend on its quality, denoted $t$, the level of managerial effort, denoted $e$, and the amount of capital allocated to the project by the headquarters, denoted $k$, according to the following specification:

$$
V=n k+\delta t k+\alpha e k-0.5 k^{2}-r k+\epsilon,
$$

where $n$ is a positive constant, $r \geq 0$ is the cost of capital, $\delta \geq 0$ measures the importance of

project quality to project cash flows, $\alpha \geq 0$ measures the importance of managerial effort to 
project cash flows, and $\epsilon$ is a noise term with mean zero. For simplicity, we assume that $n \geq r$ so that it is always worthwhile to invest some capital in the project in the socially efficient solution.

The cash flow specification, $V$, has many standard and intuitive features. Capital and effort are complementary implying that the marginal products of capital and effort are increasing in the levels of the other variable input. This assumption will be important for the main results of the paper although the specific functional form is not important. Complementary capital and effort is a very reasonable assumption if, for example, one interprets managerial effort, $e$, as labor input. Furthermore, the marginal product of capital is increasing in the quality of the project, $t$, which is intuitively appealing and implies that the headquarters will want to allocate more capital to higher quality projects. The noise term $\epsilon$ captures underlying uncertainty about or measurement errors of project cash flows and makes it impossible for headquarters to infer an exact relation between $t$ and $e$ by observing $V$. Since everyone is risk neutral in our model, the mean zero noise term and its distribution have no effect on our results. We use $E V=n k+\delta t k+\alpha e k-0.5 k^{2}-r k$ to denote the expected cash flows (expectations taken over $\epsilon$ ) for a given project quality $t$.

Headquarters does not know the true project quality $t$ but only knows that $t$ is drawn from the interval $[0, \bar{t}]$ according to a distribution $F(t)$ with density function $f(t)$, where $f(t)>0 \forall t$. We assume that $t$ and $\epsilon$ are independently distributed. As is standard in the mechanism design literature, we also assume that the hazard rate of $F(\cdot)$, denoted $\mu(t)=f(t) /(1-F(t))$, is increasing in $t$. It is well-known that many common distributions such as the uniform and (truncated) normal distribution have increasing hazard rates. Headquarters can, however, hire a division manager who is assumed to know the project quality $t$ precisely. As in Harris and Raviv (1996, 1998), we assume the manager derives utility from monetary rewards and from controlling large (high $k$ ), high-quality (high $t$ ) projects. This preference for capital may reflect enhanced reputation from controlling bigger projects, a preference for "empire-building", or greater perquisite consumption that comes from running larger businesses. Alternatively, preference for capital may be greater when the manager has project-specific human capital in which case the value of her human capital will be reduced if the project is unfunded. ${ }^{5}$

The manager also has the operational skills to enhance firm value via her effort choice $e$. The effort choice is a continuous variable which imposes costs on the manager according to the cost function $g(e)$. For tractability, we assume a specific functional form for the cost of managerial effort: $g(e)=0.5 \gamma e^{2}$, where $\gamma \geq 0$ is the manager's effort-aversion parameter.

\footnotetext{
${ }^{5}$ The assumption of a preference for capital is not necessary for the central results of the model but it does introduce greater richness into the model and is also a reasonable assumption on a priori grounds. We will establish below the results of the model which are sensitive or insensitive to this assumption.
} 
Specifically, the division manager's expected utility is given by:

$$
U=E w+\beta \delta t k-0.5 \gamma e^{2},
$$

where $w$ is her compensation, $E w$ is the expected compensation (taken over $\epsilon$ ), and $\beta \in[0,1]$ is a parameter measuring the intensity of the division manager's preference for capital. ${ }^{6}$ We also assume that the manager has outside employment opportunities offering the reservation utility $\bar{U} \geq 0$.

Headquarters' problem is to maximize the expected payoff to shareholders who are the residual claimants of the project cash flows. ${ }^{7}$ Headquarters can use two instruments to provide incentives for the division manager to tell the truth about project quality and exert proper effort: a managerial compensation contract and a capital allocation scheme. Specifically, headquarters designs an optimal mechanism consisting of a capital allocation policy $k(\hat{t})$ depending on the division manager's report about project quality, $\hat{t}$, and a compensation schedule $w(\hat{t}, V)$ depending on both the report and project outcome $V$. Importantly, we assume that the project quality $t$ is not directly observable or verifiable by the headquarters ex post therefore contracts cannot be written on $t$ directly. Moreover, the manager's effort choice is also assumed to be unobservable and unverifiable by the headquarters therefore contracts cannot be written on $e$ directly.

The sequence of moves of the game is as follows:

date 0: Headquarters offers the manager a mechanism $\{w(\hat{t}, V), k(\hat{t})\}$, and makes an effort recommendation $e(\hat{t})$.

date 1: The division manager reports $\hat{t}$.

date 2: Headquarter allocates capital of $k(\hat{t})$ to the division.

date 3: The division manager chooses effort $e$ and implements the project.

date 4: The project cash flow is realized and distributed to shareholders less the compensation $w(\hat{t}, V)$ which is paid to the division manager.

Finally, we make the standard assumption in these types of models that headquarters can commit to the capital allocation scheme offered to the manager at date $0 .{ }^{8}$

\footnotetext{
${ }^{6}$ The restriction $\beta \in[0,1]$ reflects the realistic assumption that capital has more value to the firm than to the manager. This restriction also ensures that the gross rate of return on capital, $V / k$, is increasing in $t$. Moreover, we will argue below that removing project quality from the manager's preference for capital (i.e. replacing $\beta \delta t k$ with $\beta \delta k$ ) does not impact the important qualititative results of the paper.

${ }^{7}$ We assume there are no conflicts of interest between headquarters and shareholders because these issues are not central to our thesis.

${ }^{8}$ Absent a commitment device, it would be optimal for headquarters to allocate a level of capital different
} 


\section{Benchmark Case: Symmetric Information}

To provide a benchmark, we first determine the socially efficient (first-best) solution of the model. The first-best solution maximizes the expected total surplus (expectation over $\epsilon$ ):

$$
\max _{k(t), e(t)} E V+\beta \delta t k-0.5 \gamma e^{2}=(1+\beta) \delta t k+\alpha e k-0.5 k^{2}+(n-r) k-0.5 \gamma e^{2} .
$$

Proposition 1 The first-best effort and capital allocation are given by:

$$
\begin{aligned}
e^{*}(t) & =\frac{\alpha[(1+\beta) \delta t-r+n]}{\gamma-\alpha^{2}} \\
k^{*}(t) & =\frac{\gamma[(1+\beta) \delta t-r+n]}{\gamma-\alpha^{2}}
\end{aligned}
$$

Both effort $e^{*}$ and capital allocation $k^{*}$ increase in $\alpha$ (importance of managerial effort), $\beta$ (empire-building tendency), $\delta$ (importance of project quality), $t$ (project quality), and decrease in $\gamma$ (effort-aversion) and $r$ (cost of capital).

The proof is in the Appendix. Note that we require $\gamma>\alpha^{2}$ to satisfy the second-order conditions. This parameter restriction will be assumed for the remainder of the paper. The formal derivation of the comparative statics in Proposition 1 is straightforward and thus is omitted. The intuition for these results is also straightforward. First, the marginal (social) product of capital is increasing in $\alpha, \beta, \delta$, and $t$ thus the first-best capital allocation is increasing in these parameters and decreasing in the cost of capital, $r$. Since effort and capital are complementary, the comparative statics results for $k$ imply similar comparative statics for the first-best level of effort with respect to the parameters $\alpha, \beta, \delta, t$, and $r$. Finally, the first-best effort level is decreasing in the cost of effort parameter, $\gamma$, thereby also decreasing the first-best level of capital.

In the first-best solution, the expected total surplus is simply

$$
0.5 k^{*}(t)[(1+\beta) \delta t-r+n]=0.5 \gamma[(1+\beta) \delta t-r+n]^{2} /\left(\gamma-\alpha^{2}\right) .
$$

Since $[(1+\beta) \delta t-r+n]>0$, the comparative statics of the expected total surplus are exactly the same as the capital allocation $k$.

If headquarters could observe both project quality $t$ and the division manager's effort $e$, then it should write a complete contract with the division manager that specifies the capital

than the amount offered $k(\hat{t})$ at date 0 . If, however, the manager knew this she would not report truthfully. Headquarters' commitment could be the result of (unmodelled) reputational concerns if it intends to play such a game often in the future. 
allocation $k^{*}(t)$ and effort choice $e^{*}(t)$ as in equations (1) and (2). Wages should be set to levels satisfying the division manager's participation constraint. In this case, the first- best solution is easily achieved.

\section{Optimal Mechanism: Asymmetric Information}

We now solve for the headquarters' optimal mechanism, under the assumption that headquarters does not know either project quality $t$ or managerial effort $e$. We proceed as follows. We begin by deriving the optimal mechanism under a restriction that managerial compensation contracts are linear in the project cash flows. We then show that the optimal mechanism with linear compensation contracts is in fact optimal when general contracts are permitted. In other words, there does not exist a mechanism with general compensation contracts that improves upon the mechanism we derive with linear compensation contracts.

Thus, we begin by considering managerial compensation contracts of the form:

$$
w(\hat{t}, V)=a(\hat{t})+b(\hat{t}) V
$$

with the profit sharing component $b(\cdot)$ restricted to be non-negative. It is important to note that the contract is linear in $V$ but the wage and profit-sharing components, $a(\hat{t})$ and $b(\hat{t})$, can be non-linear functions of the reported quality.

Let $U(t, \hat{t}, e)=a(\hat{t})+b(\hat{t}) E V(t, k(\hat{t}))+\beta \delta t k(\hat{t})-0.5 \gamma e^{2}$ denote the division manager's expected utility when she observes project quality of $t$, reports $\hat{t}$, and subsequently exerts effort $e$. Since the division manager chooses effort after reporting $\hat{t}$ and receiving the capital allocation $k$, she will choose effort to maximize $U(t, \hat{t}, e)$. The first-order condition is $b \alpha k=\gamma e$, therefore her optimal effort choice is given by

$$
e=\frac{\alpha b k}{\gamma}
$$

Since the objective function $U(t, \hat{t}, e)$ is strictly concave in $e$, equation (3) indeed describes the maximal solution. Substituting equation $(3)$ into $U(t, \hat{t}, e)$, we get the division manager's expected utility when she observes project quality of $t$ and reports $\hat{t}$ :

$$
\begin{aligned}
U(t, \hat{t}) & =a+b\left[\delta t k+\frac{\alpha^{2} b k^{2}}{\gamma}-0.5 k^{2}+(n-r) k\right]+\beta \delta t k-0.5 \frac{(\alpha b k)^{2}}{\gamma} \\
& =a+(b+\beta) \delta t k+b(n-r) k-0.5 b k^{2}+0.5 \frac{(\alpha b k)^{2}}{\gamma}
\end{aligned}
$$

where $\hat{t}$ is omitted in $a(\cdot), b(\cdot)$ and $k(\cdot)$. 
If the division manager reports the project quality truthfully then her expected utility is simply $U(t)=U(t, t)$. By the Revelation Principle we can, without loss of generality, restrict our attention to direct revelation mechanisms in which the division manager reports the project quality truthfully. Thus, the headquarters' mechanism design problem can be stated as:

$$
\begin{aligned}
& \max _{a(\hat{t}), b(\hat{t}), k(\hat{t})} \int_{0}^{\bar{t}}[E V-a(t)-b(t) E V] d F(t) \\
& \text { such that } \quad(i) t \in \arg \max U(t, \hat{t}) \quad(\mathrm{IC}) \\
& \text { (ii) } \forall t, U(t, t) \geq \bar{U} \quad(\mathrm{IR}) \\
& \text { (iii) } \forall t, k(t) \geq 0, \quad b(t) \geq 0 .
\end{aligned}
$$

Headquarters chooses the wage, $a(\hat{t})$, sharing-rule, $b(\hat{t})$, and capital allocation schedule, $k(\hat{t})$ to maximize the shareholders' expected profits net of compensation costs. The incentive compatibility constraint (i) imposes the condition that the division manager finds it optimal to report truthfully. The interim participation constraint (ii) imposes the condition that the division manager must achieve at least her reservation wage for all possible values of $t$. The constraint (iii) imposes the condition that the capital allocation must be non-negative and headquarters cannot give the manager a negative share of the firm.

It is important to notice that we do not impose a non-negativity constraint $a(t) \geq 0$ on the manager's wage. ${ }^{9}$ One might suspect that with unlimited liability and all parties being risk-neutral, the optimal contract would always have headquarters selling the entire firm to the manager who would then make the first-best capital allocation and effort decisions. As we noted in the Introduction, this will not generally be true in our model because we have assumed that the manager knows the project quality prior to being hired. We will show below that if the manager is offered the entire firm, she will have an incentive to misrepresent project quality to headquarters to negotiate a lower purchase price. If the manager learned project quality after being hired the optimal contract would indeed be for headquarters to sell the entire firm to her because (i) there would be no asymmetric information at the time of contracting and (ii) the risk-neutral manager is equally efficient at bearing the project quality risk as the risk-neutral headquarters.

For future reference, we provide the following definition for the values of $t_{1}$ and $t_{2}$ which will represent the boundaries for low-quality projects, $t \in\left[0, t_{1}\right)$, intermediate-quality projects, $t \in\left[t_{1}, t_{2}\right)$, and high-quality projects, $t \in\left[t_{2}, \bar{t}\right]$.

Definition Let $t_{1}$ be the solution to $[(1+\beta) \delta t-r+n] \mu(t)=\beta \delta$ and $t_{2}$ be the solution to $[(1+\beta) \delta t-r+n] \mu(t)=\delta\left(\gamma / \alpha^{2}+\beta\right)$.

\footnotetext{
${ }^{9}$ We discuss the implications of imposing such a constraint in Section 4.
} 
The assumption of an increasing hazard rate implies that the left hand sides of both equations are increasing in $t$. Hence, if a solution to either exists, it must be unique. Moreover, an increasing hazard rate implies $t_{1} \leq t_{2}$. For the rest of the paper we will assume that both solutions exist and $t_{2} \leq \bar{t}$. Furthermore, for $0 \leq t<t_{1}, 0 \leq[(1+\beta) \delta t-r+n] \mu(t)<\beta \delta$; for $t_{1} \leq t<t_{2}$, $\beta \delta \leq[(1+\beta) \delta t-r+n] \mu(t)<\delta\left(\gamma / \alpha^{2}+\beta\right)$; and for $t \geq t_{2},[(1+\beta) \delta t-r+n] \mu(t) \geq \delta\left(\gamma / \alpha^{2}+\beta\right)$.

The following proposition presents the optimal mechanism with linear compensation contracts (the proof is in the Appendix).

Proposition 2 The optimal mechanism with linear compensation contracts and its outcome can be characterized as follows.

Region 1: Low Project Quality For $t \in\left[0, t_{1}\right)$, the headquarter allocates no capital, and pays the division manager a fixed wage equal to her reservation utility:

$$
a(t)=\bar{U} ; b(t)=0 ; k(t)=0 ; e(t)=0
$$

Region 2: Intermediate Project Quality For $t \in\left[t_{1}, t_{2}\right)$, the headquarter allocates some capital, but only pays a fixed wage. The division manager exerts no effort:

$$
\begin{aligned}
a(t) & =\bar{U}+\beta \delta \int_{t_{1}}^{t} k(s) d s-\beta \delta t k(t) \\
b(t) & =0 \\
k(t) & =\frac{[(1+\beta) \delta t-r+n] \mu(t)-\beta \delta}{\mu(t)} \\
e(t) & =0
\end{aligned}
$$

Region 3: High Project Quality For $t \in\left[t_{2}, \bar{t}\right]$, the headquarter allocates more capital, and offers profit-sharing incentives. The division manager exerts effort:

$$
\begin{aligned}
a(t) & =\bar{U}+\delta \int_{t_{1}}^{t}[b(s)+\beta] k(s) d s-\delta[b(t)+\beta] t k(t)+0.5 b(t) k(t)[(1+\beta) \delta t+r-n-\beta \delta / \mu(t)] . \\
b(t) & =1-\frac{\delta \gamma / \alpha^{2}-\delta}{[(1+\beta) \delta t-r+n] \mu(t)-\delta(1+\beta)} \\
k(t) & =\frac{\gamma[(\delta t+\beta \delta t-r+n) \mu(t)-\delta(1+\beta)]}{\mu(t)\left(\gamma-\alpha^{2}\right)} \\
e(t) & =\frac{\alpha\left[(\delta t+\beta \delta t-r+n) \mu(t)-\delta\left(\gamma / \alpha^{2}+\beta\right)\right]}{\mu(t)\left(\gamma-\alpha^{2}\right)}
\end{aligned}
$$


We now give the following proposition to demonstrate that the linear compensation contracts and capital allocation rule described above implements the optimal mechanism with compensation contracts of the general form $w(\hat{t}, V)$.

Proposition 3 The optimal mechanism with linear compensation contracts cannot be improved upon with compensation contracts of the general form $w(\hat{t}, V)$.

Thus, headquarters can do no better than the mechanism described in Proposition 2. Our proof of Proposition 3 (in the Appendix) demonstrating the optimality of the linear contract follows closely the arguments of Laffont and Tirole (1986) although our model is more general. ${ }^{10}$ This result depends on our assumption of risk neutrality and the separability of effort and project quality in the cash flow specification. ${ }^{11}$

The following corollary illustrates some important features of this mechanism.

Corollary 1 Over the whole domain $[0, \bar{t}]$, the mechanism $\{a(t), b(t), k(t)\}$ and managerial effort, $e(t)$, is continuous and monotonic. $a(t)$ is non-increasing, while $b(t), k(t)$ and $e(t)$ are non-decreasing.

The optimal mechanism allocates more capital and a greater share of the firm to the manager if she reports a higher project quality. To induce truthtelling, the fixed-component of the compensation scheme, $a(t)$, is lower for higher reported project qualities. A manager will not want to overstate project quality because headquarters will compensate her with less valuable shares in the firm rather than a higher wage. In other words, headquarters disciplines the manager by asking her to "put her money where her mouth is" by forcing her to buy shares with cash when she reports a high quality. It will be helpful to look at two special cases to gain more intuition for the details of the optimal mechanism.

Example 1: No Moral Hazard In the case of no moral hazard, i.e. $\alpha=0$, managerial effort does not have an impact on the project cash flows. The only problem for headquarters is to induce the manager to report truthfully the project quality. To achieve this goal, the headquarters uses a capital allocation schedule increasing in the manager's reported project quality and pays the manager a wage decreasing in her reported project quality. Thus, the

\footnotetext{
${ }^{10}$ See also McAfee and MacMillan (1986) and Holmstrom and Milgrom (1991). Interested readers are referred to these papers for more technical details and the description of other settings in which the linear contract is optimal. Laffont and Tirole (1993) provide sufficient conditions for the optimality of linear contracts in a setting similar to our model but without moral hazard.

${ }^{11}$ The importance of the latter assumption is discussed following equation (12) in the Appendix.
} 
wage imposes discipline on the manager which prevents her from always reporting the maximum project quality. When managerial effort does not impact cash flows, it is cheaper for headquarters to induce truthful reporting from the manager by compensating her (indirectly) with capital rather than with profit-sharing because the former adds to the project cash flows while the latter does not. Consequently, headquarters optimally sets $b(t)=0$. The optimal mechanism does not yield the first-best outcome in this case as $k^{*}(t)-k(t)=\beta \delta / \mu(t)>0$ for $t \in\left[t_{1}, \bar{t}\right]$. Notice, however, that first-best can only be achieved in this case if there are no benefits of control, i.e. $\beta=0$, since the manager would then have no incentive to misrepresent the project quality. ${ }^{12}$

This example demonstrates the importance of our assumption that there is both adverse selection and moral hazard. Absent moral hazard considerations, the optimal managerial contract is trivial. Importantly, even in the absence of moral hazard first-best cannot generally be achieved because the manager still has an incentive to overstate the project quality.

Example 2: No Adverse Selection Another interesting special case is when there is no adverse selection problem, i.e. $\delta=0$. In this case, the only problem is moral hazard, and since the division manager is risk-neutral the optimal solution is to sell the project to her, $b(t)=1$. The manager will then choose the first-best capital allocation and effort and there will be no inefficiency.

In the general case where both moral hazard and adverse selection problems are present, headquarters has to strike an optimal balance between the two considerations, which is reflected in the optimal mechanism in Proposition 2. The key to understanding the optimal mechanism is the following result (derived in the proof of Proposition 2 in the Appendix) demonstrating that incentive compatibility requires:

$$
U(t)=U(0)+\delta \int_{0}^{t}[b(s)+\beta] k(s) d s .
$$

This states that to induce truthtelling a manager of type $t$ must receive utility of $U(t)$. The term $\delta \int_{0}^{t}[b(s)+\beta] k(s) d s$ represents the type- $t$ manager's information rents. These information rents are increasing in $t$. Truthtelling can be achieved with any contract yielding the manager $U(t)$, however, the cost of compensating managers with profit-sharing, $b(t)$, and capital, $k(t)$, spills over into the information rents that must be paid to all managers with higher quality projects! In other words, the marginal cost of increasing $b(t)$ and $k(t)$ for low- $t$ managers can

\footnotetext{
${ }^{12}$ This point is illustrated in a somewhat different model by Harris, Kriebel, and Raviv (1982).
} 
be exceedingly high.

The consequences of the structure of managerial information rents illuminate many of the important results of our paper. First, the marginal cost of allocating an extra unit of capital is relatively more expensive for low-quality projects because of the increased information rents that must be given to all managers of higher-quality projects. We will show below that this induces underinvestment in capital relative to first-best. Second, the marginal cost of allocating an extra unit of profit-sharing is also relatively more expensive for low-quality projects. This induces underinvestment in managerial effort relative to first-best. Moreover, this explains why the headquarters does not find it optimal to choose the mechanism $b(\hat{t})=1$ and $k(\hat{t})=k^{*}(\hat{t})$ for all $\hat{t}$. This mechanism involves selling the firm to the manager and allocating the first-best level of capital according to the manager's report. If such a contract is offered for all project types, managers of high-quality projects extract excessive rents from shareholders. Third, managerial preference for capital is not critical in our model. Specifically, if $\beta=0$ the first-best outcome cannot be achieved. The impact of assuming $\beta>0$ is that it increases the costs offering capital to lower quality projects thereby exacerbating the investment distortions. ${ }^{13}$ Finally, in the absence of asymmetric information $(\delta=0)$ headquarters can implement first-best because offering profit-sharing and capital to low-quality projects does not affect the information rents to managers of higher-quality projects. That is, the headquarters is free to choose capital and profit-sharing without worrying about the spillover effects thus first-best can be achieved.

Another interesting implication of the optimal mechanism is that firms offering high profit shares $b$ have greater values for two reasons. First, high managerial shareholdings mitigate moral hazard problems which has a causal effect on firm value. Second, high managerial shareholdings are offered only to managers of high quality projects in order to mitigate adverse selection problems and thus does not have a causal effect on firm value. This suggests that empirical studies attempting to find a causal relation between managerial incentives (e.g. payfor-performance sensitivity) and firm performance should control for factors related to adverse selection.

Finally, the following lemmas describe important properties of the no-investment region (Region 1) and the no-profit-sharing region (Region 2).

Lemma 1 Region 1 increases in $r, \delta$ and $\beta$ and is independent of $\alpha$ and $\gamma$.

Lemma 2 Region 3 decreases in $r, \delta, \gamma$ and increases in $\alpha$. The effect of $\beta$ is ambiguous.

In the no-investment region, headquarters allocates no capital to the manager even though

\footnotetext{
${ }^{13}$ Note that the $\beta$ component of the information rents will vanish if we assume the manager enjoys benefits of control $\beta \delta k$ instead of $\beta \delta t k$. Thus, under this alternative specification for managerial preferences we still get the same qualitative results but the efficiency losses in the second-best mechanism will be dampened.
} 
the first-best solution allocates positive amounts of capital for all values of $t$ in the region. The intuition for this again follows from the fact that headquarters must offer greater information rents to the manager for all higher quality projects. From equation (5) it is clear that headquarters can extract greater rents at high values of $t$, where the payoff is great, by restricting capital and profit-sharing at low values of $t$, where the payoff is small. Lemma 1 shows that Region 1 increases in $\delta, \beta$, and $r$. When $\delta$ and $\beta$ are large, the manager has a greater incentive to overstate the project quality thus the costs of allocating capital at low values of $t$ increase because headquarters is forced to offer even greater rents to the manager at high values of $t$ to induce truthtelling. Finally, since $b^{*}(t)=0$ in both Region 1 and Region 2, the parameters $\alpha$ and $\gamma$ have no marginal impact on managerial effort (which is given by $e=\alpha b k / \gamma$ ) in both regions and thus they have no effect on the boundary between Regions 1 and 2 .

Although the firm finds it optimal to allocate some capital for intermediate-quality projects (Region 2), it does not pay to offer profit-sharing in this region because the marginal cost (increased information rents must be offered for all higher project types) exceeds the marginal benefit (increased managerial effort has a small effect on value because the capital allocation is low). In fact, it is never optimal to introduce profit-sharing when $k=0$ since effort is given by (3) thus offering profit-sharing has no marginal benefit (no impact on effort when $k=0$ ) but it increases costs (increased information rents for higher project types). ${ }^{14}$ However, it may be optimal to introduce capital when $b=0$ (as in Region 2) even though it has no impact on effort because it increases the total surplus via the project cash flows and the manager's preference for capital. Lemma 2 shows that Region 2 increases in $\gamma$ and decreases in $\alpha$. The intuition for this is that the marginal benefit of increasing the profit-sharing rule $(b)$ is felt through its effect on effort which is given by $e=\alpha b k / \gamma$; thus the marginal benefit of increasing the profit-sharing rule increases in $\alpha$ and decreases in $\gamma$. Lemma 2 also shows that Region 2 increases in $r$ because an increase in $r$ lowers the capital allocation which lowers the marginal benefit of effort which in turn lowers the marginal benefit of increasing $b$.

\subsection{Comparison to First-Best Solution}

Comparing the capital allocation in the optimal mechanism with the first-best solution we find:

$$
k^{*}(t)-k(t)= \begin{cases}\frac{\gamma[(1+\beta) \delta t-r+n]}{\gamma-\alpha^{2}} & : 0 \leq t<t_{1} \\ \frac{\alpha^{2}[(1+\beta) \delta t-r+n] \mu(t)+\beta \delta\left(\gamma-\alpha^{2}\right)}{\mu(t)\left(\gamma-\alpha^{2}\right)} & : \quad t_{1} \leq t \leq t_{2} \\ \frac{\gamma \delta(1+\beta)}{\mu(t)\left(\gamma-\alpha^{2}\right)} & : t>t_{2}\end{cases}
$$

\footnotetext{
${ }^{14}$ This result is special to our cash flow specification, in particular, the assumption that effort and capital only enter multiplicatively. If effort alone entered additively it would be possible to have $b>0$ and $k=0$. Either way, the central qualitative results obtain.
} 
Consequently, there is underinvestment of capital in the optimal mechanism relative to the firstbest solution. Notice that since $\mu(t)$ is increasing in $t$ the underinvestment problem becomes smaller as $t$ increases. The intuition for this is that the marginal cost of increasing the capital allocation for high values of $t$ is small because the headquarters is then only forced to increase the allocation for the remaining values of $t<\bar{t}$ which is small. In the limit, as $t$ approaches $\bar{t}$, headquarters sells the firm to the manager who then chooses the optimal capital and effort.

This capital underinvestment result is consistent with the evidence that firms adopt higher hurdle rates of return than predicted by standard finance theory (Poterba and Summers, 1992). The traditional NPV rule for making investment decisions assumes there are no problems with the flow of information from division managers to headquarters. In our model, the division manager has an incentive to overstate project cash flows and minimize effort. In response, headquarters allocates less capital and less profit-sharing for low-quality projects to induce truthful reports and managerial effort for high-quality projects where it matters most. Consequently, the firm may either pass up positive NPV projects (Region 1) or allocate too little capital (require too high a hurdle rate) to others. Inspection reveals that the underinvestment problem is more severe when the manager's preference for capital is greater (high $\beta$ ) and when (unknown) project quality is more important to the value of the firm (high $\delta$ ). In these cases, the manager has a greater incentive to overstate project quality and the optimal mechanism responds by lowering the capital allocation.

Our underinvestment result contrasts with Harris and Raviv (1996) who found that overinvestment occurred for the lowest quality projects while underinvestment occurred for the highest quality projects. The main difference between their model and ours is that they do not allow the manager's wage to depend on project quality and instead use probabilistic auditing to discipline the manager. The substantive impact of this difference can be seen by comparing their model when auditing costs are prohibitively high to our model when $\alpha=0$ (no moral hazard as is assumed throughout their model) in which case the only difference between the two models is the role played by wage contracts. In this special case, the headquarters in Harris and Raviv's model must allocate the same amount of capital to all projects because there is no way to induce managers with different project qualities to report truthfully. Consequently, headquarters will allocate capital according to some average quality thereby overinvesting in low-quality projects and underinvesting in high-quality projects. ${ }^{15}$ Conversely, in our model the compensation contract can depend on project quality. Overinvestment is never optimal for any project quality because headquarters can increase firm value and satisfy incentive compat-

\footnotetext{
${ }^{15}$ When the auditing cost is not prohibitively high in the Harris and Raviv model, the optimal mechanism balances expected auditing costs and investment efficiency. Overinvestment continues to occur for the low quality projects to control auditing costs. As auditing costs go to zero, investment becomes efficient.
} 
ibility and participation constraints by raising the wage component and lowering the capital allocation.

Comparing managerial effort in the optimal mechanism with the first-best solution, we find:

$$
e^{*}(t)-e(t)= \begin{cases}\frac{\alpha[(1+\beta) \delta t-r+n]}{\gamma-\alpha^{2}} & : \quad 0 \leq t<t_{2} \\ \frac{\delta\left(\alpha^{2} \beta+\gamma\right)}{\alpha \mu(t)\left(\gamma-\alpha^{2}\right)} & : \quad t \geq t_{2}\end{cases}
$$

thus there is under-investment in the division manager's effort. The reason for this is clear. By equation (3), effort is increasing in the manager's share $b$ and capital $k$, but the optimal mechanism with asymmetric information offers less profit-sharing and less capital than the optimal mechanism with symmetric information.

\subsection{Comparative Statics}

The following propositions describe the comparative statics results for the optimal mechanism.

Proposition 4 The optimal capital allocation $k(t)$ increases in $\alpha$, decreases in $\gamma$, and decreases in $r$. For low project qualities $(t \mu(t)<1), k(t)$ is decreasing in $\beta$. For high project qualities $(t \mu(t)>1), k(t)$ is increasing in $\beta$. The impact of $\delta$ on $k(t)$ is as follows:

(i) For $t \in\left[t_{1}, t_{2}\right)$ and for low project qualities $((1+\beta) t \mu(t)<\beta), k(t)$ is decreasing in $\delta$, and for high project qualities $((1+\beta) t \mu(t)>\beta), k(t)$ is increasing in $\delta$.

(ii) For $t \in\left[t_{2}, \bar{t}\right]$ and for low project qualities $(t \mu(t)<1), k(t)$ is decreasing in $\delta$, and for high project qualities $(t \mu(t)>1), k(t)$ is increasing in $\delta$.

Proposition 5 The optimal sharing-rule $b(t)$ increases in $\alpha$, decreases in $\gamma$, decreases in $r$, and decreases in $\delta$. For low project qualities $(t \mu(t)<1), b(t)$ is decreasing in $\beta$ and for high project qualities $(t \mu(t)>1), b(t)$ is increasing in $\beta$.

The intuition for these results is as follows. An increase in $\alpha$ and a decrease in $\gamma$ increase the marginal benefit and decrease the marginal cost of managerial effort, respectively, making it desirable to induce greater managerial effort. From equation (3), headquarters can induce greater managerial effort by increasing either capital allocation or profit-sharing or both thus both $k(t)$ and $b(t)$ increase in $\alpha$ and decrease in $\gamma$. Clearly, an increase in the cost of capital, $r$, leads to a decrease in the optimal capital allocation. Since managerial effort and capital are complementary, it follows that a lower capital allocation reduces the marginal product of managerial effort and hence the desired level of managerial effort thus profit-sharing $b(t)$ also decreases in $r$.

An increase in the manager's control benefits, $\beta$, has two effects. On the one hand, it increases the division manager's incentives to exaggerate project quality thereby increasing 
her information rents. On the other hand, it increases the total surplus by increasing the division manager's control benefit, part of which accrues to the headquarter as it can lower the wage to the division manager. For low project qualities, the marginal incentives to lie are greater so the former effect dominates the latter and hence the optimal capital allocation $k(t)$ and profit-sharing rule $b(t)$ are both decreasing in $\beta$. For high project qualities, the marginal incentives to lie are smaller, so the latter effect dominates and the optimal capital allocation $k(t)$ and profit-sharing rule $b(t)$ are both increasing in $\beta$. If the project quality is at its maximum level $\bar{t}$, the former effect disappears completely, so an increase in $\beta$ simply increases the total surplus available.

An increase in $\delta$ increases directly the marginal productivity of capital, thus the optimal capital allocation $k(t)$ should tend to increase in $\delta$. However, this direct effect of $\delta$ on $k(t)$ is smaller for low quality projects. Additionally, $\delta$ also affects the division manager's incentives to lie about project quality. In fact, the effects of $\delta$ on the division manger's truth-telling incentives are exactly the same as those of $\beta$. Therefore, for low project qualities, the effect on the marginal incentives to lie dominates and hence the optimal capital allocation $k(t)$ decreases in $\delta$. For high project qualities, the other effects dominate and $k(t)$ increases in $\delta$. For the comparative statics on the optial profit-sharing rule $b(t)$, note the fact that it is relatively cheaper to use capital to compensate the division manager when capital is more productive. Since an increase in $\delta$ makes capital more productive, the optimal profit sharing rule $b(t)$ tends to decrease. Moreover, this effect is stronger for high project qualities. Therefore, unlike $k(t)$, $b(t)$ is decreasing in $\delta$ for any project qualities.

Finally, because managerial effort and capital are complementary, equilibrium effort $e(t)$ changes similarly to the capital allocation, i.e. effort increases in $\alpha$, decreases in $\gamma$, decreases in $r$, and is ambiguous in $\delta$ and $\beta .{ }^{16}$

The exogenous parameters in our model have reasonable empirical proxies. One reasonable proxy for the manager's preference for capital $(\beta)$ is the degree to which her human capital is firm specific because in such cases it is much more important to her that the project be funded since the next-best use of her skill is likely to be of much lower value. Another proxy for $\beta$ is the amount of free cash flow generated by the project which could be used later, for example, to finance perquisite consumption.

The importance of (unverifiable) managerial effort $(\alpha)$ also represents the degree of complementarity between managerial effort and capital which is also likely to be greater when managers have firm specific human capital. Thus our model predicts that for human capital intensive industries (e.g. drug research, software development), managers will receive greater performance-based compensation and the underinvestment problem will be more severe.

\footnotetext{
${ }^{16}$ Specifically, the optimal effort is a multiplicative function of the capital allocation, see equation (3).
} 
The importance of unobserved project quality $(\delta)$ is likely to be higher when asymmetric information between headquarters and the manager is more severe such as divisions in a large multi-divisional firm or for foreign subsidiaries where knowledge of local conditions (e.g. demand, political risks) is critical. Our model predicts that such managers will receive less performance-based compensation and the underinvestment problem will be more severe. ${ }^{17}$

The level of effort-aversion $(\gamma)$ is likely to be higher when it is more difficult to monitor the manager. Thus, $\gamma$ will be higher for projects generating cash flows far in the future, projects that take a long time to complete, or for firms operating in markets with exogeneous, random forces (e.g. volatile demands) that make it difficult to ascertain the level of managerial inputs. In such cases, our model predicts that managers will receive less performance-based pay.

In sum, our model makes a number of interesting empirical predictions about investment hurdle rates and managerial compensation contracts. Our model with capital budgeting, asymmetric information, and moral hazard is much richer than the standard agency model based on managerial moral hazard alone and therefore produces many novel cross-sectional predictions about compensation contracts. Specifically, our model shows how characteristics of the firm's investment opportunities (such as the degree of asymmetric information, generation of free cash flow, and the cash flow horizon) and determinants of managerial preference for capital (such as human capital specificity) affect the optimal compensation contract. Other predictions for managerial compensation are consistent with the standard agency models because moral hazard is also present in our model. Finally, the presence of asymmetric information tends to dampen the degree of performance-based pay relative to the simple agency model with moral hazard alone (in which case the optimal contract with risk neutral participants is to sell the firm to the manager).

\subsection{Robustness Issues}

We now consider the consequences of changing some of the assumptions in our model.

Limited Liability: In many models with a risk-neutral principal and a risk-neutral agent one must impose a limited liability constraint (in our model $a(t) \geq 0$ ) to rule out the contract in which the principal sells the firm to the agent. We demonstrated above that when the manager in our model knows $t$ prior to being offered the mechanism it is not generally optimal for headquarters to sell the firm to her even though everyone is risk neutral.

If we interpret $a(t)$ to be an up-front payoff then $a(t)$ can become negative in our model for high values of $t$ since $b(t)$ tends to one to induce optimal effort. Now consider what happens

\footnotetext{
${ }^{17}$ Consistent with our prediction, Palia (2000) finds empirical evidence that division managers of diversified firms have lower performance-based pay than managers of single-segment firms in the same industry.
} 
when the limited liability constraint becomes binding at some value $t_{L}$. Clearly $t_{L}$ depends on the reservation utility $\bar{U}$. To focus on the interesting cases, suppose $t_{L} \geq t_{2}$, i.e. is in Region 3. In the range of $\left[t_{L}, \bar{t}\right]$, the optimal mechanism involves choosing two functions $b(t)$ and $k(t)$ to maximize:

$$
\begin{aligned}
E U_{P}= & \int_{0}^{\bar{t}}\left[(1+\beta) \delta t k(t)+(n-r) k(t)-0.5 k(t)^{2}\left(1+\frac{\alpha^{2} b(t)^{2}}{\gamma}-\frac{2 \alpha^{2} b(t)}{\gamma}\right)\right] f(t) d t \\
& -\delta \int_{0}^{\bar{t}}(1-F(t))[b(t)+\beta] k(t) d t-U(0)
\end{aligned}
$$

subject to

$$
b(t) E V=U(t)-\beta \delta t k+0.5 \gamma e^{2}=U(0)+\delta \int_{0}^{t}[b(s)+\beta] k(s) d s-\beta \delta t k+0.5 \gamma e^{2} .
$$

The constraint imposes $a(t)=0$ in this range thereby restricting the feasible set of $\{b(t), k(t)\}$. A closed-form solution to this problem does not exist, however, it can be verified numerically that both $b(t)$ and $k(t)$ will be smaller than in the case without the limited liability constraint. ${ }^{18}$ For $t<t_{L}$, the solution is the same as in our original model. The reason is that the optimal mechanism maximizes the headquarters' expected payoff over the whole range of $t$, so it has to be optimal in both $\left[0, t_{L}\right]$ and $\left[t_{L}, \bar{t}\right]$. For $\left[0, t_{L}\right]$, the limited liability constraint is not binding, and hence all the previous results should hold. The link between the two subranges comes from the incentive compatibility constraint (IC). However, as long as $U(t)=U(0)+\delta \int_{0}^{t}[b(s)+\beta] k(s) d s$ holds for all $t$, the (IC) constraint is satisfied.

Effects of Risk Aversion: If the manager is risk averse it becomes more costly for headquarters to give profit-sharing compensation thus the profit-sharing component of the managerial compensation contract will fall. This causes managerial effort to fall because the manager enjoys less of the benefits of her effort which in turn reduces the optimal capital allocation since capital and effort are complementary. Thus, the underinvestment problem in capital and effort is likely to be more severe.

\section{Conclusions}

This paper examines optimal capital allocation and managerial compensation policies in a decentralized firm. Headquarters should not naively apply the NPV-rule when deciding how

\footnotetext{
${ }^{18} \mathrm{~A}$ limited liability constraint also changes the values of the boundaries between the three regions without qualitatively impacting the optimal mechanism.
} 
much capital to allocate to a project because they must depend on the reports of self-interested division managers with private information about the project quality. Because managers have a preference for larger capital allocations they have an incentive to overstate project quality to headquarters in order to secure more capital. Moreover, division managers must be given incentives to provide appropriate levels of (privately) costly effort. We find that firms will typically underinvest in capital relative to the first-best situation in which the division manager's information is known to headquarters. This prediction is consistent with empirical evidence that firms adopt much higher hurdle rates of return than required by standard finance theory (Poterba and Summers, 1992). While there are other theories that make a similar prediction (e.g. valuable timing options) we also generate novel cross-sectional predictions about the severity of the underinvestment problem and the composition of managerial compensation contracts. For example, we predict that the underinvestment problem will be more severe and managers will receive greater performance-based pay when the firm has high $\mathrm{R} \& \mathrm{D}$ expenditures and/or requires the manager to have highly firm-specific human capital. We also predict that the underinvestment problem will be more severe and managers will receive less performance-based pay in divisions of large multi-division firms or for foreign subsidiaries where knowledge of local conditions is critical. Finally, in the presence of asymmetric information and moral hazard, managers of high-quality investment projects will optimally receive more incentive-based pay than managers of low-quality projects. Thus, contrary to standard agency models based on moral hazard alone, greater performance-based pay does not necessarily cause subsequent firm performance to improve, rather managers receive greater performance-based pay because they manager higher-quality projects. This insight has important implications for the design of empirical studies of the link between the composition of managerial compensation contracts and subsequent firm performance.

There are many interesting paths for future research. We have only considered singledivision firms and have not considered how multiple divisions might change the optimal mechanism. In particular, how does the correlation of payoffs and effort complementarities across projects impact the optimal mechanism? If, for example, payoffs are uncorrelated but effort is complementary then we would expect that the optimal mechanism will involve greater incentive-based pay and greater capital allocations since the marginal benefit of increasing both increases. We have also only considered a static model and assumed that firms can commit to the optimal mechanism because of dynamic, reputational concerns. It would be very interesting to explicitly model the dynamic aspects of the capital budgeting process. For example, firms could induce truthtelling by punishing managers with lower capital allocations when previous projects performed poorly. Alternatively, if managers have a greater incentive to overstate project cash flows with longer horizons (due to the inability to discipline them in the short run) then firms may optimally impose greater penalties on long horizon cash flows. 
This could potentially explain the use of investment criteria such as IRR or payback rules which discount long-horizon cash flows heavily. ${ }^{19}$ Finally, we do not explicitly model the role of headquarters in our firm. A clearer understanding of this role will allow us to improve our understanding of the choice between external and internal capital markets.

\footnotetext{
${ }^{19}$ In a different setting, Berkovitch and Israel (1998) demonstrate that uncertainty about project scale can result in IRR or payback rules dominating the NPV rule for selecting projects.
} 


\section{APPENDIX}

Proof of Proposition 1: The first-best solution maximizes the total surplus:

$$
\max _{k(t), e(t)} E V+\beta \delta t k-0.5 \gamma e^{2}=(1+\beta) \delta t k+\alpha e k-0.5 k^{2}+(n-r) k-0.5 \gamma e^{2} .
$$

The first-order conditions are:

$$
\begin{array}{r}
(1+\beta) \delta t+\alpha e-k-r+n=0, \\
\alpha k-\gamma e=0 .
\end{array}
$$

Solving these equations gives:

$$
\begin{aligned}
e^{*}(t) & =\frac{\alpha[(1+\beta) \delta t-r+n]}{\gamma-\alpha^{2}}, \\
k^{*}(t) & =\frac{\gamma[(1+\beta) \delta t-r+n]}{\gamma-\alpha^{2}} .
\end{aligned}
$$

By our assumption $n \geq r$, the above expressions are positive if $\gamma>\alpha^{2}$.

The second order condition for the total surplus-maximization problem requires that the matrix of second derivatives of the objective function is negative semi-definite. Straightforward calculation shows that this requires $\gamma>\alpha^{2}$. If $\gamma \leq \alpha^{2}$, then the total surplus function is convex in $e$ and $k$ and hence the first-best solution does not exist.

Q.E.D.

Proof to Proposition 2: To solve the optimal mechanism design problem, we first analyze the Incentive Compatibility constraint. The IC constraint implies that:

$$
\left.\frac{\partial U(t, \hat{t})}{\partial \hat{t}}\right|_{\hat{t}=t}=0
$$

The Envelope Theorem implies:

$$
\frac{d U(t, t)}{d t}=\left.\frac{\partial U(t, \hat{t})}{\partial t}\right|_{\hat{t}=t}+\left.\frac{\partial U(t, \hat{t})}{\partial \hat{t}}\right|_{\hat{t}=t}=\left.\frac{\partial U(t, \hat{t})}{\partial t}\right|_{\hat{t}=t}=[b(t)+\beta] \delta k(t) .
$$

Integrating yields:

$$
U(t)=U(0)+\delta \int_{0}^{t}[b(s)+\beta] k(s) d s
$$


Note that $U(t)=E w+\beta \delta t k-0.5 \gamma e^{2}$, so $E w=a(t)+b(t) V=U(t)-\beta \delta t k+0.5 \gamma e^{2}$. Plugging $E w$ into the objective function of the mechanism design problem gives:

$$
\begin{aligned}
E U_{P}= & \int_{0}^{\bar{t}}\left[\delta t k(t)+\alpha e k(t)-0.5 k(t)^{2}+(n-r) k(t)-U(t)+\beta \delta t k(t)-0.5 \gamma e^{2}\right] d F(t) \\
= & \int_{0}^{\bar{t}}\left[(1+\beta) \delta t k(t)+(n-r) k(t)-0.5 k(t)^{2}\left(1+\frac{\alpha^{2} b(t)^{2}}{\gamma}-\frac{2 \alpha^{2} b(t)}{\gamma}\right)\right] f(t) d t \\
& -\int_{0}^{\bar{t}}\left[\int_{0}^{t}(b(s)+\beta) \delta k(s) d s+U(0)\right] d F(t) .
\end{aligned}
$$

Integration by parts gives:

$$
\begin{aligned}
\int_{0}^{\bar{t}}\left[\int_{0}^{t}(b(s)+\beta) \delta k(s) d s\right] d F(t) & =\left.\delta\left[\int_{0}^{t}(b(s)+\beta) k(s) d s\right] F(t)\right|_{0} ^{\bar{t}}-\delta \int_{0}^{\bar{t}} F(t)[b(t)+\beta] k(t) d t \\
& =\delta \int_{0}^{\bar{t}}[b(t)+\beta] k(t) d t-\delta \int_{0}^{\bar{t}} F(t)[b(t)+\beta] k(t) d t \\
& =\delta \int_{0}^{\bar{t}}(1-F(t))[b(t)+\beta] k(t) d t .
\end{aligned}
$$

Therefore,

$$
\begin{aligned}
E U_{P}= & \int_{0}^{\bar{t}}\left[(1+\beta) \delta t k(t)+(n-r) k(t)-0.5 k(t)^{2}\left(1+\frac{\alpha^{2} b(t)^{2}}{\gamma}-\frac{2 \alpha^{2} b(t)}{\gamma}\right)\right] f(t) d t \\
& -\delta \int_{0}^{\bar{t}}(1-F(t))[b(t)+\beta] k(t) d t-U(0) .
\end{aligned}
$$

Ignore the IR constraint for the moment, the first-order conditions are:

$$
\begin{aligned}
& \frac{\partial E U_{P}}{\partial b}=-0.5 k(t)^{2}\left(\frac{2 \alpha^{2} b(t)}{\gamma}-\frac{2 \alpha^{2}}{\gamma}\right) f(t)-\delta k(t)(1-F(t))=0 \\
& \frac{\partial E U_{P}}{\partial k}=\left[(1+\beta) \delta t-r+n-k(t)\left(1+\frac{\alpha^{2} b(t)^{2}}{\gamma}-\frac{2 \alpha^{2} b(t)}{\gamma}\right)\right] f(t)-\delta[b(t)+\beta](1-F(t))=0 .
\end{aligned}
$$

These first-order conditions can be simplified as:

$$
\begin{aligned}
\alpha^{2}(1-b(t)) k(t) \mu(t) & =\delta \gamma \\
{\left[(1+\beta) \delta t-r+n-k(t)\left(1+\frac{\alpha^{2} b(t)^{2}}{\gamma}-\frac{2 \alpha^{2} b(t)}{\gamma}\right)\right] \mu(t) } & =\delta[b(t)+\beta] .
\end{aligned}
$$

Solving for $b(t)$ and $k(t)$ from the two equations, we arrive at 


$$
\begin{aligned}
& b(t)=1-\frac{\delta \gamma / \alpha^{2}-\delta}{[(1+\beta) \delta t-r+n] \mu(t)-\delta(1+\beta)}, \\
& k(t)=\frac{\gamma[(\delta t+\beta \delta t-r+n) \mu(t)-\delta(1+\beta)]}{\mu(t)\left(\gamma-\alpha^{2}\right)} .
\end{aligned}
$$

By definition of $t_{2}$, for $t \geq t_{2},[(1+\beta) \delta t-r+n] \mu(t) \geq \delta\left(\gamma / \alpha^{2}+\beta\right)$ thus $b(t)$ given in (9) is positive but not greater than one and $k(t)$ given in (10) is positive. For these to be the optimal solutions, we also need to check the second order conditions:

$$
\begin{aligned}
& \frac{\partial^{2} E U_{P}}{\partial b^{2}}=-\frac{k(t)^{2} \alpha^{2} f(t)}{\gamma}<0, \\
& \frac{\partial^{2} E U_{P}}{\partial k^{2}}=-\left(1+\frac{\alpha^{2} b(t)^{2}}{\gamma}-\frac{2 \alpha^{2} b(t)}{\gamma}\right) f(t)<0, \\
& \frac{\partial^{2} E U_{P}}{\partial b \partial k}=-k(t)\left(\frac{2 \alpha^{2} b(t)}{\gamma}-\frac{2 \alpha^{2}}{\gamma}\right) f(t)-\delta(1-F(t))>0 .
\end{aligned}
$$

The second inequality above follows from that $b(b-2) \in[-1,0]$ and $\gamma>\alpha^{2}$, which together implies that $1+\alpha^{2} b(t)^{2} / \gamma-2 \alpha^{2} b(t) / \gamma>0$. For the second order conditions to hold, the matrix of second derivatives of $E U_{P}$ must be negative semi-definite around the solutions given in (9) and (10). This means $\left(\partial^{2} E U_{P} / \partial b^{2}\right)\left(\partial^{2} E U_{P} / \partial k^{2}\right)-\left[\partial^{2} E U_{P} /(\partial b \partial k)\right]^{2} \geq 0$. Some calculation reveals that the left-hand side equals $\left[(1-F(t)]^{2}\left[\delta^{2}\left(\gamma-\alpha^{2}\right)\right] /\left[\alpha^{2}(1-b(t))^{2}\right]\right.$ at the solutions given in (9) and (10), which clearly is greater than zero. So the second order condition is satisfied.

When $t<t_{2},[(1+\beta) \delta t-r+n] \mu(t)<\delta\left(\gamma / \alpha^{2}+\beta\right)$ implying that the non-negativity constraint on $b(t)$ from equation (9) is binding. With $b(t)=0$, from $\partial E U_{P} / \partial k=0$, we can solve for $k(t)$ :

$$
k(t)=\frac{[(1+\beta) \delta t-r+n] \mu(t)-\delta \beta}{\mu(t)} .
$$

For $t \in\left[t_{1}, t_{2}\right)$, the non-negativity constraint on $k(t)$ from equation (10) is not binding. From the fact that $\partial^{2} E U_{P} / \partial k^{2}<0$, this is indeed a maximal solution for $t \in\left(t_{1}, t_{2}\right]$. For any $t<t_{1}$, the non-negativity constraint on $k(t)$ is binding, so both $b(t)$ and $k(t)$ will be zero in this range of $t$. This is clearly optimal since $E U_{P}$ is decreasing in $k(t)$.

Now let us turn to the participation constraint. Obviously $U(0)$ should be set to equal $\bar{U}$. It is easy to see that both $b(t)$ and $k(t)$ are non-decreasing in the interval $\left[t_{2}, \bar{t}\right]$. Therefore, it follows from (8) that the division manager's utility is increasing in $t$. So as long as the participation constraint is satisfied when $t=0$, it is satisfied for every $t$. 
From the optimal $b(t)$ and $k(t)$, equation (3) gives the effort choice by the division manager. Since $b(t)=0$ for $t<t_{2}$, e will also be zero in this range. For $t \geq t_{2}$, we have:

$$
e(t)=\frac{\alpha\left[(\delta t+\beta \delta t-r+n) \mu(t)-\delta\left(\gamma / \alpha^{2}+\beta\right)\right]}{\mu(t)\left(\gamma-\alpha^{2}\right) .}
$$

From (4) and (8), we can derive $a(t)$, the fixed portion of the wage schedule as follows:

$$
a(t)=\bar{U}+\delta \int_{0}^{t}[b(s)+\beta] k(s) d s-\left[\delta(b+\beta) t k+b(n-r) k-0.5 b k^{2}+0.5 \frac{(\alpha b k)^{2}}{\gamma}\right]
$$

Since both $b(t)$ and $k(t)$ are continuous, $a(t)$ is continuous. For $t \in\left[0, t_{1}\right)$, clearly this simplifies to $a(t)=\bar{U} \geq 0$. For $t \in\left[t_{1}, t_{2}\right), b(t)=0$ and $k(t)$ is given by (11), thus

$$
a(t)=\bar{U}+\beta \delta \int_{t_{1}}^{t} k(s) d s-\beta \delta t k .
$$

Note that $a\left(t_{1}\right)=\bar{U}-\beta \delta t_{1} k\left(t_{1}\right)=\bar{U}$. Furthermore, it is easy to see that $a(t)$ is strictly decreasing in $\left(t_{1}, t_{2}\right)$ since $a^{\prime}(t)=-\beta \delta t k^{\prime}(t)<0$.

For $t \in\left[t_{2}, \bar{t}\right), b(t)$ and $k(t)$ are given by (9) and (10), thus $a(t)$ is given by

$$
\begin{aligned}
a(t) & =\bar{U}+\delta \int_{t_{1}}^{t}[b(s)+\beta] k(s) d s-\delta(b+\beta) t k-0.5 b k\left[\alpha^{2} b k / \gamma-k+2(n-r)\right] \\
& =\bar{U}+\delta \int_{t_{1}}^{t}[b(s)+\beta] k(s) d s-\delta(b+\beta) t k+0.5 b k[(1+\beta) \delta t+r-n-\beta \delta / \mu(t)] .
\end{aligned}
$$

Substituting the derived mechanism into $U(t, \hat{t})$, it is straightforward to show:

$$
\left.\frac{\partial^{2} U(t, \hat{t})}{\partial \hat{t}^{2}}\right|_{\hat{t}=t}=-\frac{d}{d \hat{t}}[\delta(b(\hat{t})+\beta) k(\hat{t})]_{\hat{t}=t}
$$

which is negative from the monotonicity of the mechanism. Therefore, the first-order approach is applicable to this case (Rogerson, 1985).

Q.E.D.

Proof of Proposition 3: The proof follows closely the arguments in Laffont and Tirole (1986). We will determine the optimal general mechanism under the assumption that $\epsilon \equiv 0$. This gives headquarters the added flexibility to choose the level of managerial effort according to the manager's report by punishing her when the final cash flow deviates from its deterministic value. We will then show that the headquarters expected payoff in this setup is the same as 
in our model with the linearity restriction, therefore, we can conclude that the linear contract implements the optimal mechanism.

Let $\epsilon \equiv 0$ in which case the final cash flow is deterministic. Now consider a general mechanism $\{w(\hat{t}, V), k(\hat{t}), e(\hat{t})\}$ which gives headquarters the added ability to impose any level of effort $e$ by punishing (with arbitrary severity) the manager if the final cash flow is different from that which would obtain if the true quality is as reported and effort is not the level requested.

Given the capital allocation rule $k(\hat{t})$, define

$$
U(t, \hat{t}, e)=w(\hat{t}, V)+\beta \delta t k(\hat{t})-0.5 \gamma e^{2}
$$

as the division manager's payoff when the project quality is $t$ and she announces $\hat{t}$ and exerts effort of $e$.

By the Revelation Principle we can, without loss of generality, restrict our attention to direct revelation mechanisms in which the division manager reports the project quality truthfully and follows the effort recommendation $e(t)$ obediently. Then the headquarters' mechanism design problem can be stated as

$$
\begin{aligned}
& \max _{k(t), e(t), w(t, V)} \int_{0}^{\bar{t}}[V-w(t, V)] d F(t) \\
& \text { such that } \quad(i) t, e(t) \in \arg \max U(t, \hat{t}, e) \quad(\mathrm{IC}) \\
& (\text { ii }) \forall t, U(t, t, e(t)) \geq \bar{U} \quad(\mathrm{IR}) \\
& (\text { iii }) \forall t, k(t) \geq 0, \quad e(t) \geq 0 .
\end{aligned}
$$

Suppose the division manager with a project quality $t$ can deviate from $(t, e(t))$ only to some other $(\hat{t}, \hat{e})$ such that the final project value is $V(\hat{t}, \hat{t}, e(\hat{t})) \equiv V(\hat{t}) \equiv(n-r) k(\hat{t})+\delta \hat{t} k(\hat{t})+$ $\alpha e(\hat{t}) k(\hat{t})-0.5 k^{2}(\hat{t})$. This is the only possible deviation that the manager will consider because otherwise they will be subject to (arbitrarily severe) penalty from headquarters. That is, the division manager with a project quality $t$ can pretend to have a project quality of $\hat{t}$ only if he gets exactly the project value that a truthful division manager with a project quality $\hat{t}$ would get. Since

$$
V(t, \hat{t}, \hat{e})=(n-r) k(\hat{t})+\delta t k(\hat{t})+\alpha \hat{e} k(\hat{t})-0.5 k^{2}(\hat{t})
$$

then $V(t, \hat{t}, e(\hat{t}))=V(\hat{t})$ implies

$$
\hat{e}=e(\hat{t})+\delta(\hat{t}-t) / \alpha
$$


Thus, to avoid penalty from headquarters any deviation from truthful reporting also requires a specific deviation of managerial effort from that requested by headquarters as given by (12). Note that our cash flow specification assumes a certain "substitutability" between effort and project quality (they do not enter multiplicatively) which ensures a linear relationship between effort deviations and reporting deviations in (12) which greatly simplifies the remainder of the proof. In particular, it greatly helps to establish the monotonicity of the truth-telling utility in (14) to follow.

If the division manager can only deviate to those $(\hat{t}, \hat{e})$ that satisfy equation (12), the (IC) condition can be rewritten as

$$
t \in \arg \max U(t, \hat{t})=w(\hat{t}, V(\hat{t}))+\beta \delta t k(\hat{t})-0.5 \gamma[e(\hat{t})+\delta(\hat{t}-t) / \alpha]^{2}
$$

By the Envelope Theorem, this (IC) condition of equation (13) implies

$$
\frac{d U(t, t)}{d t}=\left.\frac{\partial U(t, \hat{t})}{\partial t}\right|_{\hat{t}=t}+\left.\frac{\partial U(t, \hat{t})}{\partial \hat{t}}\right|_{\hat{t}=t}=\left.\frac{\partial U(t, \hat{t})}{\partial t}\right|_{\hat{t}=t}=\beta \delta k(t)+\gamma \delta e(t) / \alpha .
$$

Integrating yields:

$$
U(t)=U(0)+\delta \int_{0}^{t}[\beta k(s)+\gamma e(s) / \alpha] d s .
$$

Note that $U(t)=w+\beta \delta t k-0.5 \gamma e^{2}$, so $w=U(t)-\beta \delta t k+0.5 \gamma e^{2}$. Plugging $w$ into the objective function of the mechanism design problem gives:

$$
\begin{aligned}
E U_{P}= & \int_{0}^{\bar{t}}\left[\delta t k(t)+\alpha e(t) k(t)-0.5 k(t)^{2}+(n-r) k(t)-U(t)+\beta \delta t k(t)-0.5 \gamma e^{2}(t)\right] d F(t) \\
= & \int_{0}^{\bar{t}}\left[(1+\beta) \delta t k(t)+(n-r) k(t)+\alpha e(t) k(t)-0.5 k(t)^{2}-0.5 \gamma e^{2}(t)\right] f(t) d t \\
& -\int_{0}^{\bar{t}}\left[\int_{0}^{t}[\beta \delta k(s)+\delta \gamma e(s) / \alpha] d s+U(0)\right] d F(t) .
\end{aligned}
$$

Integration by parts gives:

$$
\begin{aligned}
\int_{0}^{\bar{t}}\left[\int_{0}^{t}[\beta \delta k(s)+\delta \gamma e(s) / \alpha] d s\right] d F(t) & =\left.\delta\left[\int_{0}^{t}[\beta k(s)+\gamma e(s) / \alpha] d s\right] F(t)\right|_{0} ^{\bar{t}}-\delta \int_{0}^{\bar{t}} F(t)[\beta k(t)+\gamma e(t) / \alpha] d t \\
& =\delta \int_{0}^{\bar{t}}[\beta k(t)+\gamma e(t) / \alpha] d t-\delta \int_{0}^{\bar{t}} F(t)[\beta k(t)+\gamma e(t) / \alpha] d t \\
& =\delta \int_{0}^{\bar{t}}(1-F(t))[\beta k(t)+\gamma e(t) / \alpha] d t .
\end{aligned}
$$

Therefore, 


$$
\begin{aligned}
E U_{P}= & \int_{0}^{\bar{t}}\left[(1+\beta) \delta t k(t)+(n-r) k(t)+\alpha e(t) k(t)-0.5 k(t)^{2}-0.5 \gamma e^{2}(t)\right] f(t) d t \\
& -\delta \int_{0}^{\bar{t}}(1-F(t))[\beta k(t)+\gamma e(t) / \alpha] d t-U(0) .
\end{aligned}
$$

Ignore the IR constraint for the moment, the first-order conditions are:

$$
\begin{aligned}
& \frac{\partial E U_{P}}{\partial e}=[\alpha k(t)-\gamma e(t)] f(t)-\delta \gamma(1-F(t)) / \alpha=0 \\
& \frac{\partial E U_{P}}{\partial k}=[(1+\beta) \delta t-r+n-k(t)+\alpha e(t)] f(t)-\delta \beta(1-F(t))=0 .
\end{aligned}
$$

Solving for $e(t)$ and $k(t)$ from the two equations, we arrive at

$$
\begin{array}{r}
e(t)=\frac{\alpha\left[(\delta t+\beta \delta t-r+n) \mu(t)-\delta\left(\gamma / \alpha^{2}+\beta\right)\right]}{\mu(t)\left(\gamma-\alpha^{2}\right)} \\
k(t)=\frac{\gamma[(\delta t+\beta \delta t-r+n) \mu(t)-\delta(1+\beta)]}{\mu(t)\left(\gamma-\alpha^{2}\right)}
\end{array}
$$

By definition of $t_{2}$, for $t \geq t_{2},[(1+\beta) \delta t-r+n] \mu(t) \geq \delta\left(\gamma / \alpha^{2}+\beta\right)$ thus $e(t)$ given in (15) and $k(t)$ given in (16) are both positive.

When $t<t_{2},[(1+\beta) \delta t-r+n] \mu(t)<\delta\left(\gamma / \alpha^{2}+\beta\right)$ implying that the non-negativity constraint on $e(t)$ from equation (15) is binding. With $e(t)=0$, from $\partial E U_{P} / \partial k=0$, we can solve for $k(t)$ :

$$
k(t)=\frac{[(1+\beta) \delta t-r+n] \mu(t)-\delta \beta}{\mu(t)} .
$$

For $t \in\left[t_{1}, t_{2}\right)$, the non-negativity constraint on $k(t)$ from equation (16) is not binding. For any $t<t_{1}$, the non-negativity constraint on $k(t)$ is binding, so both $e(t)$ and $k(t)$ will be zero in this range of $t$. For these to be the optimal solutions, we still need to check the second order conditions. This is trivial as $E U_{P}$ is strictly concave in $(e, k)$ when $\gamma>\alpha^{2}$.

Now let us turn to the participation constraint. Obviously $U(0)$ should be set to equal $\bar{U}$. It is easy to see that both $e(t)$ and $k(t)$ are non-decreasing on $[\underline{t}, \bar{t}]$. Therefore, it follows from (14) that the division manager's utility is increasing in $t$. So as long as the participation constraint is satisfied when $t=0$, it is satisfied for every $t$.

Since the headquarters has more flexibility with this general mechanism, its expected payoff should be at least as great as the original mechanism in Proposition 2. Note that the optimal $k(t)$ and $e(t)$ derived here are identical to those in Proposition 2. In this program, we have set $\epsilon \equiv 0$ and given headquarters greater flexibility, yet its expected payoff is identical to that 
under the assumption of linear contracts with random $\epsilon$. Therefore, the solution for the relaxed program is implemented by the linear compensation contract and the capital allocation rule in Proposition 2. Moreover, from the derivation of Proposition 2 (in particular, equation 3), clearly the division manager of project quality $t$ does not want to deviate from $(t, e(t))$ to any other $(\hat{t}, e)$ under the linearity restriction. Thus we can conclude that the linear compensation contract and the capital allocation rule in Proposition 2 implement the optimal mechanism with general contracts.

Q.E.D.

Proof of Lemma 1: Denote

$$
H(t)=[(1+\beta) \delta t-r+n] \mu(t)-\beta \delta .
$$

Since $t_{1}$ satisfies $H\left(t_{1}\right) \equiv 0$,

$$
\frac{d t_{1}}{d r}=-\frac{H_{r}}{H_{t}}=-\frac{-\mu}{(1+\beta) \delta \mu(t)+[(1+\beta) \delta t-r+n] \mu^{\prime}}>0
$$

where the inequality follows immediately from the fact that $\mu(t)$ is increasing in $t$. Also

$$
\frac{d t_{1}}{d \delta}=-\frac{H_{\delta}}{H_{t}}=-\frac{(1+\beta) t \mu(t)-\beta}{(1+\beta) \delta \mu(t)+[(1+\beta) \delta t-r+n] \mu^{\prime}} .
$$

From $H\left(t_{1}\right)=0$ and $n>r,(1+\beta) t \mu(t)-\beta<0$, therefore $\frac{d t_{1}}{d \delta}>0$. Also,

$$
\frac{d t_{1}}{d \beta}=-\frac{H_{\beta}}{H_{t}}=-\frac{\delta t \mu(t)-\delta}{(1+\beta) \delta \mu(t)+[(1+\beta) \delta t-r+n] \mu^{\prime}} .
$$

From $H\left(t_{1}\right)=0$ and $n>r, t \mu(t)-1<0$, therefore $\frac{d t_{1}}{d \beta}>0$.

Q.E.D.

Proof of Lemma 2: Denote

$$
G(t)=[(1+\beta) \delta t-r+n] \mu(t)-\delta\left(\frac{\gamma}{\alpha^{2}}+\beta\right) .
$$


Since $t_{2}$ satisfies $G\left(t_{2}\right) \equiv 0$,

$$
\frac{d t_{2}}{d r}=-\frac{G_{r}}{G_{t}}=-\frac{-\mu}{(1+\beta) \delta \mu(t)+[(1+\beta) \delta t-r+n] \mu^{\prime}}>0
$$

where the inequality follows immediatly from the fact that $\mu(t)$ is increasing in $t$. Similarly we have $\frac{d t_{2}}{d \alpha}<0$ and $\frac{d t_{2}}{d \gamma}>0$. Also,

$$
\frac{d t_{2}}{d \delta}=-\frac{G_{\delta}}{G_{t}}=-\frac{(1+\beta) t \mu(t)-\left(\gamma / \alpha^{2}+\beta\right)}{(1+\beta) \delta \mu(t)+[(1+\beta) \delta-r+n] \mu^{\prime}}
$$

From $G\left(t_{2}\right)=0$ and $n>r,(1+\beta) t \mu(t)-\left(\gamma / \alpha^{2}+\beta\right)<0$, therefore $\frac{d t_{2}}{d \delta}>0$. Also,

$$
\frac{d t_{2}}{d \beta}=-\frac{G_{\beta}}{G_{t}}=-\frac{\delta t \mu(t)-\delta}{(1+\beta) \delta \mu(t)+[(1+\beta) \delta-r+n] \mu^{\prime}}
$$

which cannot be unambiguously signed.

Q.E.D.

Proof of Corollary 1: The monotonicity of $b(t)$ and $k(t)$ follows immediately from the assumption of $\frac{d \mu(t)}{d t}>0$ and $n>r$. The derivation is trivial.

To prove the monotonicity of $a(t)$ recall that for $t_{1}<t<t_{2}$ we have:

$$
a(t)=\bar{U}+\beta \delta \int_{t_{1}}^{t} k(s) d s-\beta \delta t k
$$

Differentiating yields:

$$
\frac{d a}{d t}=\beta \delta k-\beta \delta\left(k+t k^{\prime}\right)=-\beta \delta t k^{\prime}<0
$$

where the inequality follows from the fact $k^{\prime}>0$.

For $t>t_{2}$ we have:

$$
a(t)=\bar{U}+\delta \int_{t_{1}}^{t}[b(s)+\beta] k(s) d s-\delta(b+\beta) t k+0.5 b k[(1+\beta) \delta t+r-n-\beta \delta / \mu(t)] .
$$

Differentiating yields: 


$$
\begin{aligned}
d a(t) / d t= & \delta[b(t)+\beta] k(t)-\delta(b+\beta) k-\delta b^{\prime} t k-\delta(b+\beta) t k^{\prime} \\
& +0.5\left(b^{\prime} k+b k^{\prime}\right)[(1+\beta) \delta t+r-n-\beta \delta / \mu(t)]+0.5 b k\left[(1+\beta) \delta+\beta \delta \mu^{\prime} / \mu^{2}\right] \\
= & -0.5 b^{\prime} k[(1-\beta) \delta t+n-r+\beta \delta / \mu] \\
& -0.5 b k^{\prime}[(1-\beta) \delta t+n-r+\beta \delta / \mu]-\delta \beta t k^{\prime}+0.5 b k\left[(1+\beta) \delta+\beta \delta \mu^{\prime} / \mu^{2}\right]
\end{aligned}
$$

The first term is negative as $b^{\prime}>0$. So we must demonstrate that all the other terms add up to a negative value too. Using the fact that:

$$
k^{\prime}(t)=\frac{\gamma\left[(1+\beta) \delta+\delta(1+\beta) \mu^{\prime} / \mu^{2}\right]}{\left(\gamma-\alpha^{2}\right)}
$$

and $b \leq 1$, we have:

$$
\begin{aligned}
& -0.5 b k^{\prime}[(1-\beta) \delta t+n-r+\beta \delta / \mu]-\delta \beta t k^{\prime}+0.5 b k\left[(1+\beta) \delta+\beta \delta \mu^{\prime} / \mu^{2}\right] \\
\leq & -0.5 b k^{\prime}[(1-\beta) \delta t+n-r+\beta \delta / \mu]-b \delta \beta t k^{\prime}+0.5 b k\left[(1+\beta) \delta+\beta \delta \mu^{\prime} / \mu^{2}\right] \\
= & -\frac{0.5 b \gamma}{\gamma-\alpha^{2}}\left\{\left[(1+\beta) \delta+\delta(1+\beta) \mu^{\prime} / \mu^{2}\right][(1-\beta) \delta t+n-r+\beta \delta / \mu]\right. \\
& \left.+2 \delta \beta t\left[(1+\beta) \delta+\delta(1+\beta) \mu^{\prime} / \mu^{2}\right]-[(1+\beta) \delta t-r+n-\delta(1+\beta) / \mu]\left[(1+\beta) \delta+\beta \delta \mu^{\prime} / \mu^{2}\right]\right\} \\
= & -\frac{0.5 b \gamma}{\gamma-\alpha^{2}}\left\{\left[(1+\beta) \delta+\delta(1+\beta) \mu^{\prime} / \mu^{2}\right][(1-\beta) \delta t+n-r+\beta \delta / \mu]\right. \\
& \left.+2 \delta^{2} \beta t \mu^{\prime} / \mu^{2}-[(1-\beta) \delta t-r+n-\delta(1+\beta) / \mu]\left[(1+\beta) \delta+\beta \delta \mu^{\prime} / \mu^{2}\right]\right\} \\
= & -\frac{0.5 b \gamma}{\gamma-\alpha^{2}}\left\{\delta \mu^{\prime} / \mu^{2}[(1-\beta) \delta t+n-r+\beta \delta / \mu]+2 \delta^{2} \beta t \mu^{\prime} / \mu^{2}\right. \\
& \left.+[\beta \delta / \mu+\delta(1+\beta) / \mu]\left[(1+\beta) \delta+\beta \delta \mu^{\prime} / \mu^{2}\right]\right\} \\
= & -\frac{0.5 b \gamma}{\gamma-\alpha^{2}}\left\{\delta \mu^{\prime} / \mu^{2}[(1+\beta) \delta t+n-r+2 \beta(1+\beta) \delta / \mu]+(1+\beta)^{2} \delta^{2} / \mu+(1+\beta) \delta^{2} \beta / \mu\right\} \\
< & 0
\end{aligned}
$$

Therefore $a(t)$ is decreasing in $t$.

Q.E.D.

Proof of Proposition 4 We will derive the result keeping the boundaries of Regions 1, 2, and 3 fixed. It is straightforward to show that the boundaries of these regions move in the appropriate direction so that the results apply generally.

For $t \in\left[0, t_{2}\right)$ the capital allocation is independent of $\alpha$ and $\gamma$. For $t \in\left[t_{2}, \bar{t}\right]$ : 


$$
\begin{aligned}
\frac{\partial k}{\partial \alpha} & =\frac{\gamma[(\delta t+\beta \delta t-r+n) \mu(t)-(1+\beta) \delta]}{\mu(t)} \frac{2 \alpha}{\left(\gamma-\alpha^{2}\right)^{2}}>0, \\
\frac{\partial k}{\partial \gamma} & =\frac{(\delta t+\beta \delta t-r+n) \mu(t)-(1+\beta) \delta}{\mu(t)} \frac{-\alpha^{2}}{\left(\gamma-\alpha^{2}\right)^{2}}<0,
\end{aligned}
$$

thus $k(t)$ is increasing in $\alpha$ and decreasing in $\gamma$.

For $t \in\left[t_{1}, t_{2}\right), \frac{\partial k}{\partial r}=-1$ and for $t \in\left[t_{2}, \bar{t}\right], \frac{\partial k}{\partial r}=-\frac{\gamma}{\gamma-\alpha^{2}}$ thus $k(t)$ is decreasing in $r$.

For $t \in\left[t_{1}, t_{2}\right), \frac{\partial k}{\partial \delta}=\frac{(1+\beta) t \mu(t)-\beta}{\mu(t)}$. Notice that $\mu(t)$ is increasing in $t$. Therefore, for low project qualities $((1+\beta) t \mu(t)<\beta), k(t)$ is decreasing in $\delta$, and for high project qualities $((1+\beta) t \mu(t)>\beta), k(t)$ is increasing in $\delta$.

For $t \in\left[t_{2}, \bar{t}\right] \frac{\partial k}{\partial \delta}=\frac{\gamma(1+\beta)(t \mu(t)-1)}{\mu(t)\left(\gamma-\alpha^{2}\right)}$. Similarly for low project qualities $(t \mu(t)<1), k(t)$ is decreasing in $\delta$, and for high project qualities $(t \mu(t)>1), k(t)$ is increasing in $\delta$.

For $t \in\left[t_{1}, t_{2}\right), \frac{\partial k}{\partial \beta}=\frac{\delta(t \mu(t)-1)}{\mu(t)}$ and for $t \in\left[t_{2}, \bar{t}\right], \frac{\partial k}{\partial \beta}=\frac{\gamma \delta(t \mu(t)-1)}{\mu(t)\left(\gamma-\alpha^{2}\right)}$. Therefore, for low project qualities $(t \mu(t)<1), k^{*}(t)$ is decreasing in $\beta$, and for high project qualities $(t \mu(t)>1)$, $k(t)$ is increasing in $\beta$.

Q.E.D.

Proof of Proposition 5 As in Proposition 4, we will derive the result keeping the boundaries of Regions 1, 2, and 3 fixed. It is straightforward to show that the boundaries of these regions move in the appropriate direction so that the results apply generally.

For $t \in\left[0, t_{2}\right)$ we have $b(t)=0$. For $t \in\left[t_{2}, \bar{t}\right]$ :

$$
\begin{aligned}
\frac{\partial b}{\partial \alpha} & =\frac{2 \delta \gamma}{\alpha^{3}} \frac{1}{[(1+\beta) \delta t-r+n] \mu(t)-\delta(1+\beta)}>0 \\
\frac{\partial b}{\partial \gamma} & =-\frac{\delta}{\alpha^{2}} \frac{1}{[(1+\beta) \delta t-r+n] \mu(t)-\delta(1+\beta)}<0 \\
\frac{\partial b}{\partial r} & =-\frac{\mu(t)\left(\delta \gamma / \alpha^{2}-\delta\right)}{[[(1+\beta) \delta t-r+n] \mu(t)-\delta(1+\beta)]^{2}}<0 \\
\frac{\partial b}{\partial \delta} & =-\frac{\mu(t)\left(\gamma / \alpha^{2}-1\right)(-r+n)}{[[(1+\beta) \delta t-r+n] \mu(t)-\delta(1+\beta)]^{2}}<0
\end{aligned}
$$

and 


$$
\frac{\partial b}{\partial \beta}=\frac{\delta^{2}\left(\gamma / \alpha^{2}-1\right)(t \mu(t)-1)}{[[(1+\beta) \delta t-r+n] \mu(t)-\delta(1+\beta)]^{2}}
$$

Note that $\mu(t)$ is increasing in $t$, therefore, for low project qualities $(t \mu(t)<1), b(t)$ is decreasing in $\beta$, and for high project qualities $(t \mu(t)>1), b(t)$ is increasing in $\beta$.

Q.E.D. 


\section{References}

[1] Antle, R., Eppen, G., 1995. Capital rationing and organizational slack in capital budgeting. Management Science 31, 163-174.

[2] Berkovitch, E., Israel, R., 1998. Why the NPV criterion does not maximize NPV. Unpublished working paper. Tel Aviv University.

[3] Gertner, R.H., Scharfstein, D.S., Stein, J.C., 1994. Internal versus external capital markets. Quarterly Journal of Economics 109, 1211-1230.

[4] Grossman, S., Hart, O., 1982. Corporate financial structure and managerial incentives. In: McCall, J. (Ed.), The Economics of Information and Uncertainty. University of Chicago Press, Chicago, pp. 107-137.

[5] Harris, M., Raviv, A., 1996. The capital budgeting process: Incentives and information. Journal of Finance 51, 1139-1174.

[6] Harris, M., Raviv, A., 1998. Capital budgeting and delegation. Journal of Financial Economics 50, 259-289.

[7] Harris, M., Kriebel, C.H., Raviv, A., 1982. Asymmetric information, incentives, and intrafirm resource allocation. Management Science 28, 604-620.

[8] Holmstrom, B., Milgrom, P., 1987. Aggregation and linearity in the provision of intertemporal incentives. Econometrica 55, 597-619.

[9] Holmstrom, B., Ricart i Costa, J., 1986. Managerial incentives and capital management. Quarterly Journal of Economics 101, 835-860.

[10] Jensen, M., 1986. Agency costs of free cash flow, corporate finance, and takeovers. American Economic Review 76, 323-329.

[11] Laffont, J.-J., Tirole, J., 1986. Using cost observation to regulate firms. Journal of Political Economy 94, 614-641.

[12] Laffont, J.-J., Tirole, J., 1993. A Theory of Incentives in Procurement and Regulation. MIT Press, Cambridge.

[13] McAfee, R. P., McMillan, J., 1987. Competition for agency contracts. RAND Journal of Economics 18, 296-307.

[14] Milbourn, T., Thakor, A., 1996. Intrafirm capital allocation and managerial compensation. Unpublished working paper. Indiana University. 
[15] Palia, D., 2000. Corporate governance and the diversification discount: Evidence from panel data. Unpublished working paper. Columbia University.

[16] Poterba, J., Summers, L., 1992. Time horizons of American firms: New evidence from a survey of CEOs. Unpublished working paper. Harvard University.

[17] Rogerson, W., 1985. The first-order approach to principal-agent problems. Econometrica $53,1357-1367$.

[18] Stein, J.C., 1997. Internal capital markets and the competition for corporate resources. Journal of Finance 52, 111-133.

[19] Zhang, G., 1997. Moral hazard in corporate investment and the disciplinary role of voluntary capital rationing. Management Science 43, 737-750. 